far more than a million people a year. A huge museum is in course of erection in Philadelphia. The great museum in Munich is famous. It is, by the way, interesting that this pioneering institution should have been founded in the city where Count Rumford served the State of Bavaria so notably. For it was he who conceived the idea of the science museum and wrote elaborately on its objects and its management. This was a hundred and thirty years ago : and it could not be improved upon now. The Royal Institution was founded in the attempt to give form to his ideas. It failed to do so because the times were not ripe; but that is no longer the case. The Faraday Exhibition of last September drew fifty thousand visitors in the ten days of its activity. I had occasion recently to visit a smaller but similar exhibition arranged in the new laboratories at Exeter ; five thousand people visited it in two or three days. The public has not only a newly wakened interest in science, but also is delighted to see actual demonstrations. This is all the better because so much of the interest has been excited by written description or by talks over the ether, and the visible example is much needed as a corrective.
Such exhibitions are of proved value, and may be extremely useful under the conditions of to-day. If any effort were made to follow examples set elsewhere, to demonstrate visually to John Citizen the slow unfolding of Nature's laws by patient research, the discovery of unsuspected beauties of order and adaptation, the origin of new conceptions of the universe, and, not least, the skilful handling of new knowledge for the service and delight of man, then the university laboratories would naturally be looked to for help. To them it would fall, as it fell to the Royal Institution, to illustrate particularly the development of scientific ideas and methods.

We cannot ask that everyone shall be trained to understand and follow the advance of scientific knowledge. All that can be worked for-and it is far from our present attainment-is that there shall be an understanding of what science is, of what it can do, and of what it cannot do. Even this cannot be expected from the public as a whole: but it is urgently necessary in these days that a sufficient number shall be so informed, and especially those whose collective opinions and wishes determine the general courses of action.

\title{
Clouds High in the Stratosphere
}

\section{By Prof. S. Chapman, F.R.S.}

$\mathrm{T}^{\mathrm{H}}$ HREE years ago, Prof. C. Størmer, of Oslo, made a preliminary announcement in NATURE of photographic observations by himself and his assistants upon the height and colour-distribution of some clouds at a remarkably great height in the atmosphere nearly over Oslo.1 ${ }^{1}$ He has now issued a detailed account of this work, ${ }^{2}$ and also of some hitherto unpublished visual observations on similar clouds, made by him on Jan. 1 and Jan. 15, 1890. The memoir is very fully illustrated by 140 dia. grams and eleven beautiful photographs, three of which are reproduced herewith.

The clouds were of the type termed in English iridescent; in German, the language in which Prof. Størmer's memoir is written, they are called Perlmutterwolken (mother-of-pearl clouds). The simile appears to be an apt one for the more luminous parts of the clouds, which present one of the most beautiful spectacles afforded by the sky. The colours and colour changes observed in these clouds are stated to be " essentially different" from the ordinary iridescence often seen at the edges of thin clouds near the sun. They are also very different from the bluish whiteness of the luminous night clouds, at about $80 \mathrm{~km}$. height according to Jesse, which Størmer states have often been seen by him. Very detailed descriptions are given as to the changing colour distribution of the clouds, especially for those of January 1890 ; the colours are mainly arranged in bands following the outlines of the clouds, and these bands, and the outlines, in some cases change rapidly, so that before a sketch of them is completed the earlier part of the sketch no longer represents the form of that section of the cloud.

Apart from their extreme beauty, the clouds are distinguished for their great height; this was suspected by the late Prof. H. Mohn, who specially studied these clouds, but it was first definitely confirmed by Prof. Størmer in 1927, who was able, on Dec. 30,1926 , to take two pairs of simultaneous photographs of such clouds from his auroral stations at Oslo and Oskarsborg. The height found was between $26 \mathrm{~km}$. and $30 \mathrm{~km}$. The new photographic material for the clouds of Jan. 13, 1929, is much more ample, the number of pairs of photographs exceeding ninety. The heights then found lie between $23 \mathrm{~km}$. and $26 \mathrm{~km}$. The existence of clouds at this high level had never previously been established. Ordinary clouds are almost entirely confined to the troposphere, that is, below about $10 \mathrm{~km}$. These mother-of-pearl clouds are high up in the stratosphere.

Yet another peculiarity of these clouds is their rarity ; Prof. Størmer saw them in 1890 , but from 1892 until the end of 1926 , though carefully watching for them, he failed to find any. In 1929 he again saw them. The conditions under which they were seen were similar in the three cases, and agreed with those described by Mohn, as associated with nearly all his observations of the clouds. They occur when there is a deep barometric depression near Oslo, and usually to the north; owing to the distribution of the mountains in the adjacent region, warm dry winds (Föhn) then often blow down the southerly and easterly slopes towards Oslo, and produce high temperatures, and a clear sky, over a part of the cyclonic area which is usually overclouded. Hence Størmer suggests that the high clouds may in fact be common features in the stratosphere over the ascending part of cyclones, but usually invisible. If this 


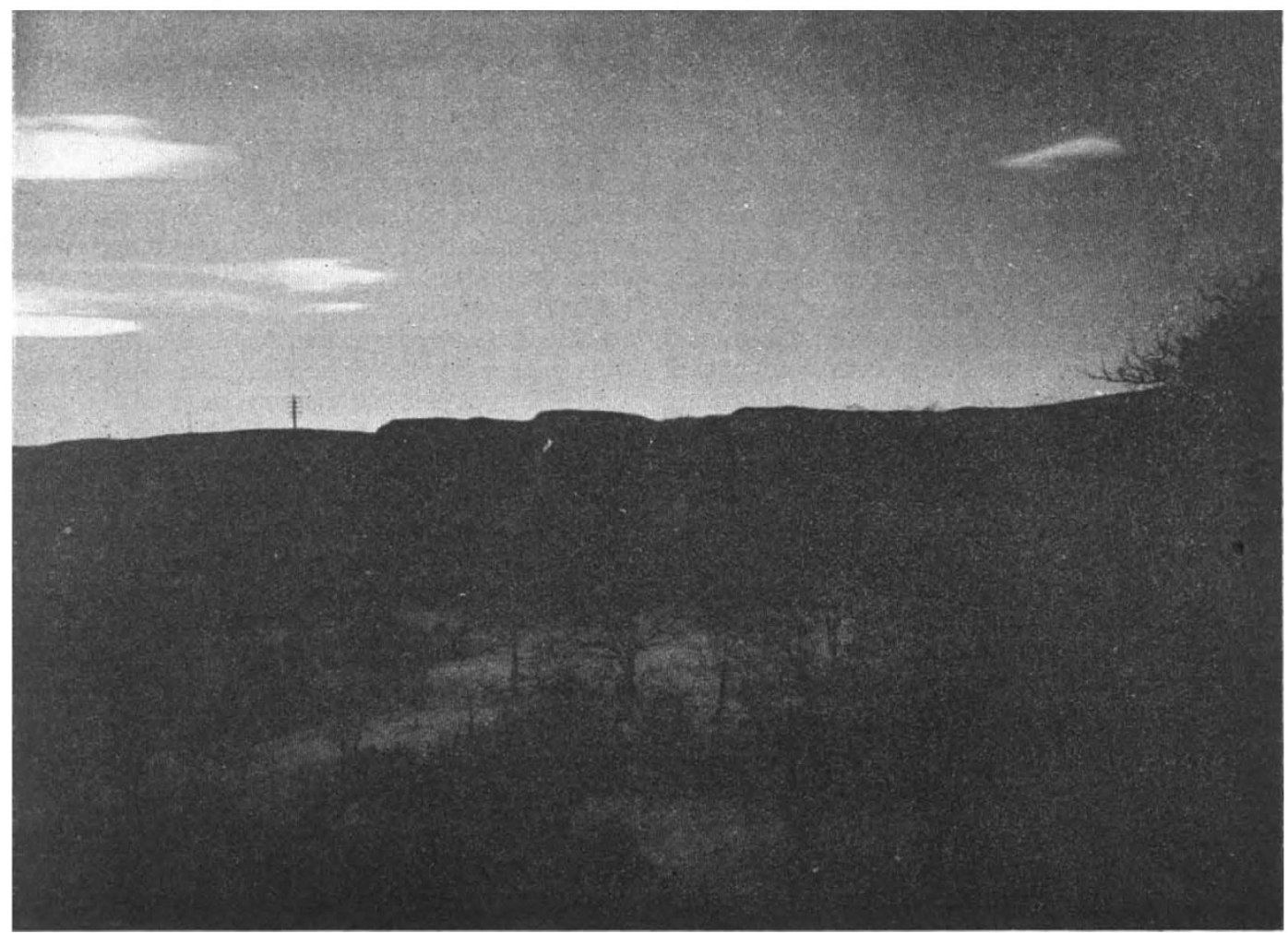

FIG. 1.-Iridescent clouds to the west-north-west, after sunset on Jan. 13, 1929.

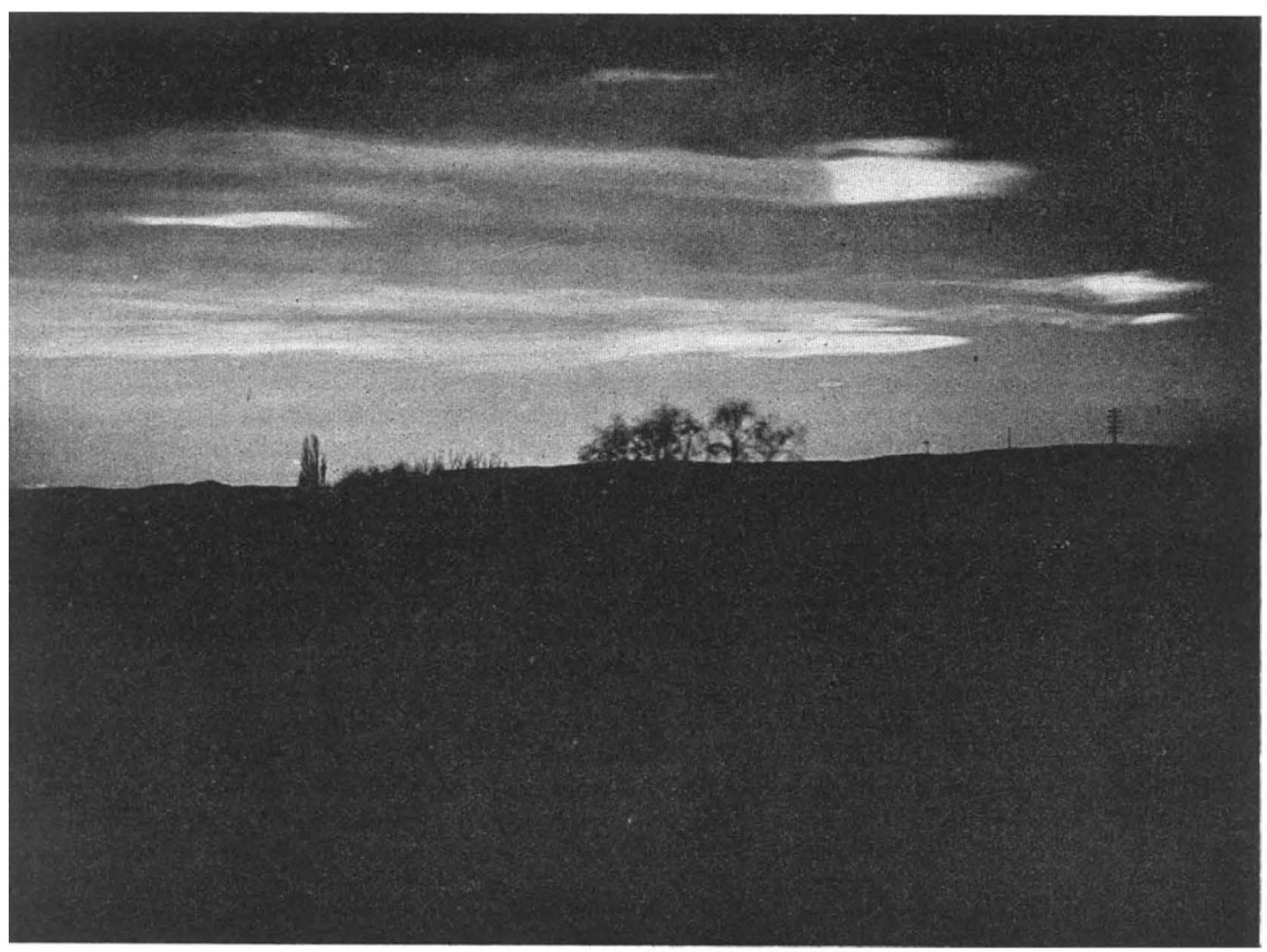

FIG. 2.-Iridescent clouds to the west-south-west, on Jan. 13, 1929. 
suggestion could be tested by aeroplane observations above the clouds during cyclones (though this may offer great difficulty) it would be of great interest.

Visual observations of the clouds seen in December 1926 indicated the very high velocity of 75 metres a second (170 miles an hour). Those of January 1929 were nearly stationary, though near the ground there was a strong north-westerly wind; "the mother-of-pearl clouds lay over Ostland [a district near Oslo] for a time longer than that needed by the lower air to travel from southern Norway to Germany '. Those of January 1890 seemed to be nearly stationary as a whole, a second, during the $1 \frac{1}{4}$ hours of duration. If this be interpreted as their steady rate of fall subject only to gravity and the resistance of stationary air, it enables the size of the cloud particles to be estimated roughly, assuming that they have the density of water and are spherical. Applying Stokes's formula, the result is $0.005 \mathrm{~cm}$. radius, but this value is near the upper limit for which, in these circumstances, Stokes's formula is applicable. The radius of ordinary cloud particles is about $0.001 \mathrm{~cm}$. It is, of course, uncertain whether the substance forming the mother-of-pearl clouds is water, though it is difficult to see what else it could be. Iridescence is currently interpreted as

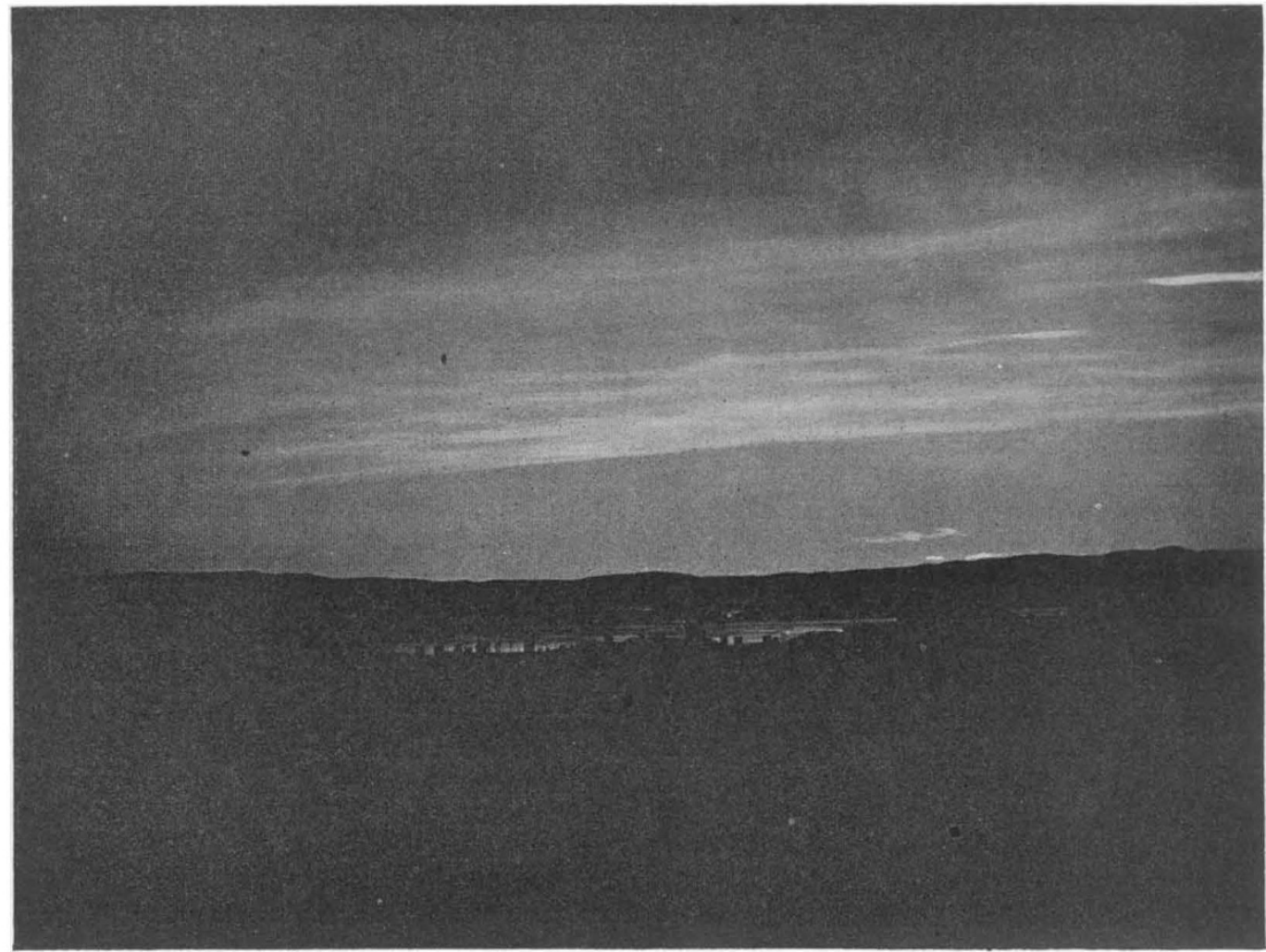

FIG. 3.-Iridescent clouds to the south-west, on Jan. 13, 1929.

but, like those of 1929 (though in a higher degree), they showed rapid internal motion, constantly breaking up or changing their shape. This is of interest as tending to confirm the view that convection or eddying motion does not cease at the top of the troposphere, but may extend far up into the stratosphere, at least to a sufficient degree to maintain a uniform mixture of the permanent constituents of the air up to a considerable height. Hitherto the most direct support for this idea has been the distorted meteor trails sometimes observed, generally at greater heights than $30 \mathrm{~km}$. Prof. Størmer's observations on these high clouds of 1890 seem to afford valuable independent confirmation of this view.

The photographs of one small cloud, of January 1929 , indicate a slow velocity of descent, of $30 \mathrm{~cm}$. indicating the presence of supercooled waterdrops.

The physical implications of the presence of these clouds at their considerable height in the stratosphere are, and for some time may remain, obscure; but possibly they will play a significant part, along with such other remarkable facts as those of the ozone relations with surface weather, in unravelling the mysterious and important problem of the origin of cyclones. However this may prove, Prof. Størmer is to be congratulated on this new achievement in precise upper atmospheric investigation, an interesting and important byproduct of the organisation he has built up for the study of the aurora borealis.

1 NATURE, 123, 260, Feb. 16, 1929

2 Geofysiske Publikasjoner, vol. 9, No. 4, Oslo, 1932; 27 pp. and 16 plates; $7.00 \mathrm{kr}$.

$$
\text { No. 3257, Vou. 129] }
$$

